\title{
La construcción social del conocimiento: Alternativa en la educación
}

\section{The knowledge social construction: An alternative in education}

Jorge Mendoza García

Universidad Pedagógica Nacional

\section{Resumen}

En este trabajo se argumentan varias cuestiones sobre la construcción social del comportamiento: 1) la discusión sobre la mente desde dos visiones distintas, la individualista y la psicocultural; 2) desde la postura psicocultural, se arguye la relevancia e importancia del uso de herramientas y signos en la configuración de la mente; 3) se discute la preeminencia del lenguaje y el diálogo en el intercambio de ideas y el saber entre las personas, y su implicación en la configuración del conocimiento y la realidad social; 4) se caracteriza el uso de cierto tipo de lenguaje, las palabras, en contextos determinados, y el uso de otro tipo de lenguaje, el de conceptos, independiente del contexto; 5) con estos cuatro postulados anteriores se discute la propuesta de la construcción social del conocimiento, que es una forma alternativa, una tendencia crítica de abordar el aprendizaje en la educación. Esta perspectiva se caracteriza por poner el acento en el lenguaje como práctica social, es decir, le otorga cierta relevancia a las prácticas discursivas que los profesores y alumnos usan en el salón de clase. Al final, se enuncian algunos ejes de trabajo desde esta propuesta.

Palabras clave: psicología cultural, mente, lenguaje, educación, construcción del conocimiento.

Nota del autor

Jorge Mendoza García, Licenciatura en Psicología Educativa, Universidad Pedagógica Nacional (UPN).

La correspondencia en relación con este artículo debe dirigirse a Jorge Mendoza García, Licenciatura en Psicología Educativa, UPN, carretera al Ajusco, número 24, Delegación Tlalpan, colonia Héroes de Padierna, C. P. 14200, Ciudad de México, D. F., México.

Dirección electrónica: jorgeuk@unam.mx 


\begin{abstract}
In this written is argued many things about the knowledge of social construction: 1) the discussion about the mind from two different views: the individualist one and the psico-cultural one; 2) from psico-cultural stance is argued the importance and relevance of the signs'andtools'use in the mind configuration; 3) is discussed the language and dialogue pre-eminence in the ideas' interchange and the knowledge among people and its implication in the knowledge and social reality configuration; 4) it is characterized the use of an specific type of language, the words in a determined contexts and the use of another type of language which is the one of the concepts without context; 5) with these four late postulates is discussed the knowledge social construction purpose which is an alternative way. A critique tendency of tackling the learning in education nowadays. This perspective is characterized for putting the accent in language as a social practice. This also give an specific relevance to the discursive practices that are used in the classroom by teachers and pupils. At the end are outlined some job core ideas from this purpose.
\end{abstract}

Keywords: cultural psychology, mind, language, education, knowledge construction.

\section{Lo psicológico y la mente: dos miradas}

Desde la psicología se puede hablar al menos de dos grandes vertientes sobre cómo concebir los procesos psicológicos, o la mente y sus derivaciones, en el campo de la educación. Por un lado, se encuentra la perspectiva, cuya hipótesis sostiene que la vida mental cobra su forma a partir del desarrollo de las personas en un determinado contexto o medio, enfatiza al individuo; el desarrollo biológico y personal es en buena medida antecedente del desarrollo mental y de las posibilidades de dominio de ciertos conocimientos. Para Jean Piaget (1991), por ejemplo, no era relevante la mente, lo eran la inteligencia y el conocimiento, desde ahí se posicionó y argumentó sus postulados. Se infiere que su formación en el campo de la ciencia natural, lo llevó a subrayar el aspecto biológico del desarrollo para explicar la adquisición del conocimiento en las personas, de manera especial en infantes; "como biólogo, su formación como tal no lo abandonó jamás y reutilizó, ajustándolos, numerosos conceptos provenientes de esa disciplina" cuando arribó a la psicología (Medina, 2007, p. 13).

$\mathrm{Su}$ perspectiva individualista ha sido una versión dominante en psicología, al menos durante una buena parte del siglo XX. A la par de esta visión, en la segunda y tercera década, se desarrolló otra perspectiva, la cultural o sociohistórica, como se conoce la escuela que Lev S. Vygotsky inauguró. Para ésta, los procesos psicológicos superiores, como la percepción, el razonamiento lógico, el pensamiento y la memoria, se encuentran mediados por herramientas, instrumentos, que son de creación social, y como productos de la actividad humana a lo largo de su historia (Vygotsky, 1932). Tal actividad se despliega en la esfera social, es decir, entre la gente, en díadas, en grupos, en comunidades, 
de ahí que dicha demostración se denomine intermental (Wertsch, 1991). Se hace referencia a actividades que se desarrollan primero en el ámbito social para después actuar en la esfera de lo personal: "en el desarrollo cultural del niño, toda función aparece dos veces: primero, a nivel social, y más tarde, a nivel individual; primero entre personas (interpsicológica), y después, en el interior del propio niño (intrapsicológica)" (Vygotsky, 1932, p. 94, cursivas en el original). Al hablar de "toda función", el autor alude a lo que él denomina "procesos psicológicos superiores". Estas funciones psicológicas superiores tienen su origen en la cultura y no en las personas como comúnmente se cree. En esa traza de reflexión, se encuentra la propuesta de Mijail, Bajtín y su escuela (1979), que pone especial énfasis en el lenguaje y el diálogo como vehículos que permiten dar cuenta del pensamiento, de la conciencia y de la sociedad. La cultura y la colectividad serán clave en su trabajo. Ambos autores, con sus escuelas, confluyen en la propuesta aquí suscrita.

En la psicología tradicional e individual, incluso parte de la social, comolanorteamericana, se estudian los procesos mentales o superiores en un vacío cultural, como si se tratara de individuos aislados, tipo laboratorio. Hay perspectivas que reducen la actividad al individuo y a su interacción con el entorno físico. En ese sentido, puede advertirse que los psicólogos suelen no mirar el contexto, situación, sea ésta política, social o ideológica. Justamente ahí lo social de la mente suele constituirse: no es gratuito que, por ejemplo, integrantes de la Escuela de Frankfurt, marxistas, filósofos y sociólogos, voltearan a la psicología social para explicar fenómenos políticos e históricos como el autoritarismo; se dieron a la tarea de comprender eventos cruentos que requerían de una explicación vasta, para lo cual no era suficiente el paradigma marxista vigente. En lo cultural, en lo social y sus relaciones y procesos, encontraron parte de la respuesta.

Pues bien, en el caso de la mente, hay una explicación sobre su edificación y funcionamiento desde un marco sociocultural, lo cual implica cuatro supuestos: 1) que se piensa de una manera, con contenidos y esquemas distintos si se trata de un país occidental a si se trata de uno no occidental, 2) que en el tiempo, por ejemplo en el medioevo, el pensamiento, contenido $\mathrm{y}$ realidad social eran distintos del pensamiento del siglo XX, 3) que en situaciones, contextos $\mathrm{y}$ devenires microsociales distintos, sus integrantes pensarán de manera distinta según su marco de referencia, aun estando en la misma sociedad o país, dadas las condiciones y grupos donde han estado inscritos, y 4) que la mente se encuentra por fuera del individuo, esto es, se va edificando en las relaciones entre las personas y mediante el lenguaje que se usa. Eso es lo sociocultural de la mente. Vista así la idea de la mente, hay psicología sociocultural en el Wilhelm Wundt (1912) de la psicología de los pueblos y en George H. Mead (1934) del espíritu, persona y sociedad. Por consiguiente, se entiende la nomenclatura que a partir de la psicología 
cultural, se utiliza en otras disciplinas. En $L a$ interpretación de las culturas, Clifford Geertz (1973) habla de la mente como algo más allá de la piel, en dos sentidos: 1) la mente puede ser grupal, la psicología social ha dado cuenta de ello, e incluso en tiempos y sociedades amplias; 2) lo mental va constituyéndose y se define por instrumentos mediadores como el lenguaje, para realizar alguna actividad. Ahí hay cultura.

Se traen a colación aquí los trabajos de Wundt (1912), Mead (1934) y Geertz (1973) por que la mirada de la psicología debe depositarse más allá de sus fronteras disciplinarias, dictadas por el positivismo imperante, toda vez que el diálogo con otras disciplinas, como antaño ocurría, posibilita la amplitud y riqueza de miras. Precisamente en este tipo de mirada se inscribió Vygotsky y su grupo. La vía vygotskyana de trabajo es lo que podemos denominar transdisciplinar o, mejor aún, desdisciplinada. Cierto, parece que a determinadas psicologías y a ciertos psicólogos les gusta la delimitación de su campo de estudio y les incomoda el diálogo con otras disciplinas. No obstante, cuando se trata de la mente humana, ello resulta una complicación cuando no un demérito en el conocimiento. El hecho de darle un abordaje semiótico otorgó posibilidades amplias a esta perspectiva, lo mismo sucedió con Bajtín, Voloshinov (1929) y Mead (1934), pues a la agudeza de sus visiones contribuyó al vínculo con estudiosos y trabajos de otras disciplinas. Todo lo anterior posibilitó que se enunciara la mente con propiedades sociales y mediadoras.

\section{Dos elementos de la cultura: herramientas y signos}

Para dar cuenta del origen social de la mente, la cultura y el lenguaje jugaron un papel nodal en el análisis de Vygotsky (1934). Lo mismo que la interacción comunicativa y el contexto. En su trabajo hay tres supuestos: 1) un análisis genético y/ o evolutivo; 2) las funciones mentales de las personas son en primera instancia sociales; y 3) la acción humana se encuentra mediada por herramientas y signos. En el primer caso, lo genético evolutivo lleva al análisis de los cambios históricos y personales a lo largo de la humanidad y del desarrollo de las personas. Para el segundo, el origen social de la mente, con base en Carlos Marx, Vygotsky sostiene que "la naturaleza psíquica de los seres humanos representa el conjunto de las relaciones sociales interiorizadas que se han convertido en funciones para el individuo, y forman la estructura del individuo" (en Wertsch, 1991, p. 43). En consecuencia, planteará que las funciones psicológicas superiores aparecen primero en el plano social, interpsicológico o intermental, y después en el plano personal, intrapsicológico o intramental. Las relaciones sociales, relaciones entre las personas, son la base de estas funciones y sus derivaciones.

Vale una nota aclaratoria: la internalización de la que se habla no es algo que se presenta en el mundo externo, una cosa ya existente, y que después se lleva al plano interno, intramental. Se trata, en este caso, de la constitución lingüística de lo psicológico con clara delineación social, 
ética y retórica. Pertenecer a un grupo o colectividad implica saber cómo actuar desde la postura de ese grupo: pensar, sentir, hablar, comportarse y hacer inteligible el mundo; en consecuencia, la perspectiva de un grupo de niños de la calle es diferente a la perspectiva de un grupo de científicos sociales tanto en su discurso como en su visión de la vida. Lo común entre los integrantes de un grupo es una serie de procedimientos semióticos, maneras de comprender y maneras de comunicar. En todo caso, la internalización es un movimiento al terreno práctico de lo cultural en una sociedad (Shotter, 1993). El propio Vygotsky (1932) ha señalado que incluso en el plano denominado privado las personas mantienen el funcionamiento de la interacción social, siendo el pensamiento una muestra de ello.

Lasaccionesylamenteseencuentranmediadas por herramientas (herramientas técnicas) y por signos (herramientas psicológicas). En este rubro la influencia del pensamiento de Carlos Marx (1932) y Federico Engels (1867) es evidente, por ejemplo, lo referente al papel del trabajo y el lenguaje en la vida social y mental. De Engels proviene la idea de "mediación instrumental" en la esfera del trabajo, nuestro autor la lleva al campo psicológico como "herramientas técnicas" y "herramientas psicológicas". Las primeras pueden ser instrumentos o herramientas (como un pizarrón, una pluma) y las segundas, los signos. Entre ambas encontró semejanzas, dada su capacidad mediadora. De la herramienta dijo: "sirve como conductor de la influencia humana sobre el objeto de su actividad. Está dirigida al mundo externo; deben estimular algunos cambios en el objeto; es un medio de la actividad externa humana dirigido a subyugar la naturaleza" (en Wertsch, 1988, pp. 93-94). En efecto, la herramienta conecta la actividad entre las personas y su entorno, así como las personas mismas. Un alumno de Vygotsky, Aleksei N. Leontiev, dirá: "la herramienta media la acción y por consiguiente conecta a los humanos no sólo con el mundo de los objetos. Sino también con otras personas; a causa de ello, la actividad de los seres humanos asimila la experiencia de la humanidad" (en Wertsch, 1997, p. 184, cursivas en el original). Es decir, al usar una herramienta, como un martillo, no sólo se hace uso del martillo sino de una larga historia de actividades que al martillo se le endosan, verbigracia, que sirva como arma mortal o como fuente de amenaza o apoyo para otra acción. Siguiendo esta lógica, en su método genético planteaba un problema a resolver, por ejemplo con infantes, e introducía instrumentos mediadores que ayudaran a la resolución de dicho problema, esa fue una aportación. En dicho sentido, "el agente de la acción mediada se concibe como el individuo o los individuos que actúan en conjunción con instrumentos mediadores" (Wertsch, 1991, p. 50).

Un instrumento mediador que ha impactado grandemente la cultura es la escritura, la cual ha sido de especial relevancia en la edificación del conocimiento y la memoria de las sociedades. Tomemos como ejemplo este caso: "las incisio- 
nes primarias que nuestros antepasados hacían en un árbol, los nudos que se hacían para recordar, vienen a ser los antecesores de nuestra escritura actual" (Vygotsky, 1931, p. 259). Tenían la misma función: convocar al recuerdo. La escritura va constituyendo y ampliando, entre otros procesos psicológicos y ámbitos de la cultura, la memoria. De hecho, se puede aseverar que "la escritura surge como guarda del recuerdo" (Lampolski, 2009, p. 80). La escritura posibilita a tal proceso psicológico superior, la memoria, desdoblarse, desplegarse en conmemoraciones y celebraciones de eventos considerados importantes. La escritura, con imprenta de por medio, siglos después, posibilitó el mantenimiento de sucesos pasados significativos para una cultura o sociedad: el conocimiento en libros. Los libros, en cierta medida, han sido una especie de recipiente donde se guarda lo que no se quiere olvidar, lo que se desea comunicar y lo que un grupo o sociedad anhela recordar. Contribuye al ensanchamiento del conocimiento, pasado y presente, traducido más tarde en enseñanza escolar.

Ahora bien, se plantean tres ideas sobre la herramienta y el signo. Una, existe una analogía entre herramienta y signo, y es su función mediadora. Segunda, hay una diferencia, pues orientan de manera distinta la actividad humana: "la función de la herramienta no es otra que la de servir de conductor de la influencia humana en el objeto de la actividad", se encuentra "externamente orientada y debe acarrear cambios en los objetos. Es un medio a través del cual la actividad humana externa aspira a dominar y triunfar sobre la naturaleza" (Vygotsky, 1932, p. 91, cursivas en el original). El signo, por su parte, "no cambia absolutamente nada en el objeto de una operación psicológica. Así pues, se trata de un medio de actividad interna que aspira a dominarse a sí mismo; el signo por consiguiente está internamente orientado" (Vygotsky, 1932, p. 92, cursivas en el original). Tercera, hay un vínculo ontogenético y filogenético: "el dominio de la naturaleza y el de la conducta están sumamente relacionados, puesto que la alteración de la naturaleza por parte del hombre altera, a su vez, la propia naturaleza del hombre" (Vygotsky, 1932, p. 92). Sobre la herramienta y el signo, al final, dirá que el uso de medios artificiales, esto es la forma mediada, modifica esencialmente las funciones psicológicas, al tiempo que "el uso de herramientas ensancha de modo ilimitado la serie de actividades dentro de las que operan las nuevas funciones psicológicas", de esta forma "podemos emplear el término de función psicológica superior, o conducta superior, al referirnos a la combinación de herramienta y signo en la actividad psicológica" (Vygotsky, 1932, p. 92, cursivas en original).

La mediación o actividad mediada, ya fuera con herramientas o signos, es una de las contribuciones de Vygotsky para la comprensión de la vida mental en la cultura: "la creación y utilización de signos como método auxiliar para resolver un problema psicológico determinado (recordar, comparar algo, relatar cosas, elegir, 
etc.), es un proceso análogo a la creación y utilización de instrumentos en lo que al aspecto psicológico se refiere”, por lo demás, "el signo actúa como un instrumento lo hace en el trabajo" (Vygotsky, 1932, p. 88). Las herramientas psicológicas son sociales, culturales, no individuales, provienen, en muchos de los casos, de un desarrollo histórico-cultural. Las personas acceden a esas herramientas debido a que se encuentran en un medio sociocultural que lo permite, se apropian de ellas: herramientas psicológicas más semióticamente orientadas, como el lenguaje, esquemas, técnicas mnemónicas, arte, entre otras.

En esta caso, a nuestra ayuda puede venir Charles Sanders Peirce (citado en FernándezChristlieb, 1994, p. 53), para quien un signo es "una cosa que está para alguien en el lugar de otra cosa bajo ciertos aspectos o capacidades", algo similar a lo que Mijail Bajtín (1979) señala: un signo es algo que representa otro objeto o suceso distinto para alguien, por ejemplo hablantes. Vygotsky (1932) habla de los sistemas de signos, como el lenguaje, los diagramas o la aritmética, también pudiera ser el sistema numérico, y su poder mediacional en las funciones intermentales e intramentales, o bien, como mediadores de la acción humana. Pongamos un ejemplo, los niños que emplean tarjetas con colores para relacionar éstos con objetos, las tarjetas ayudan, en cierta edad, a dirigir la actividad, como recordar. Las tarjetas con colores son herramientas técnicas cuyas propiedades mediadoras sígnicamente apoyan la resolución de un problema particular. Tales herramientas y signos benefician al mediar la acción con los demás o con uno mismo, lo cual constituye un tipo de mediación. Otro tipo lo representa el lenguaje. pondrá especial énfasis y fuerza en esa forma verbal, que en el caso de los adultos guía buena parte de su actividad.

Al paso del tiempo, nuestro autor puso un mayor énfasis en el significado y la comunicación de los signos. Señaló que "la función primaria del lenguaje, tanto para el adulto como para el niño, es la función comunicativa, el contacto social, la influencia sobre los individuos que nos rodean", es en ese sentido que "un signo siempre es originariamente un medio usado con propósitos sociales, un medio para influenciar a los otros, y sólo más tarde se convierte en un medio para influenciarnos a nosotros mismos" (Vygotsky, en Wertsch, 1991, p. 51). No obstante, debemos señalar que existe una diferencia significativa entre el signo y otras herramientas; los instrumentos de producción, en tanto son usados en tareas y tienen cuerpo físico, para su uso carecen de significado. El signo vehiculiza significados, es su tarea.

Los signos externos se traducen en instrumentos subjetivos de la relación con uno mismo al interiorizarse: autodirigen y regulan la conducta y el pensamiento de las personas. Los procesos psicológicos superiores, como la memoria y el pensamiento, se encuentran mediatizados por signos que los organizan y dirigen. Por pasos, lo anterior se representaría de la siguiente manera: Primero, la regulación de la 
acción de la gente llega de fuera, es externa, la orientación proviene del mundo, de la cultura; en un segundo momento, la regulación es interpersonal, de tipo díada: el adulto organiza la actividad del infante; en un tercer momento, el signo hablado se internaliza y regula la actividad de manera intramental. Dicha reconstrucción en el plano del dominio personal no se despliega de forma mecánica ni automática, ocurre, por ejemplo, como en el caso del lenguaje. Los aspectos del lenguaje desplegados en el mundo externo se llevan al plano de la regulación para sí (egocéntrico es llamado), es decir, es un lenguaje como el soliloquio, donde uno es su propio destinatario. Surge cuando el infante habla aunque no se dirige a alguna otra persona, sino que es un lenguaje para sí, o cuando se mueven los labios ante el ruido externo que imposibilita la concentración, y el habla es para uno. Sólo después este lenguaje egocéntrico se mueve al plano del pensamiento (Vygotsky, 1932). Aún en este nivel, el interiorizado, cuando el infante se habla a sí mismo a manera de monólogo, reproduce diálogos del mundo externo, tiene pautas sociales interiorizadas. Los adultos 1o hacen cuando por la mañana planean su día, y no emiten sonido alguno, lo están pensando.

En esta perspectiva, al usar una palabra se hace presente toda la carga cultural inscrita en ella. Piénsese en la palabra "psicología", en todo lo que representa: primero se encuentra en el mundo, en la esfera social e imaginaria, dando cuenta de una especie de magos de la mente; en un segundo momento, alguien nos la comunica con todo y su carga; y en un tercer momento la manejamos en el terreno práctico para designar a alguien o algo. Como todo signo, dicha palabra no sólo designa un objeto, va más allá, pues transmite un contenido cultural (Eco, 2000). Usamos ciertas palabras y no otras para, por ejemplo, designar el mundo, sus habitantes y sus relaciones.

Con base en este entramado, Wertsch (1997) amplia tales nociones, al aludir los juegos de herramientas para afirmar una relación entre procesos psicológicos y lo sociohistórico $\mathrm{y}$ cultural, tal acción posibilita ensanchar el conjunto de opciones a las cuales las personas y grupos pueden acudir para enfrentar ciertas situaciones, como la manera de comunicarse en determinada situación o de moverse en ciertos escenarios, esto es saber qué decir en un congreso y qué en la casa, y comportarse de una manera en el primero y de otra en la segunda. De esos elementos parte el autor para argumentar la historicidad de ciertos contenidos, para determinar el por qué un grupo pone atención en ciertas formas de conocimiento y lenguaje y no en otras; limitar sus posibilidades a ciertos espacios, o elegir una entre tantas formas para comunicar un acontecimiento. Elegimos ciertas palabras y no otras para hablar con nuestros familiares, verbigracia, en una discusión científica no se suele hablar con frases de sentido común o jerga coloquial.

De esta forma, Wertsch (1997) propone los denominados "textos verbales complejos", es decir, "descripciones y explicaciones de sucesos 
que evolucionaron sociohistóricamente", y que llevan a realizar ciertas narrativas de una forma y no de otra. Ahí pueden incluirse desde los reportes científicos o la manera cómo se escribe una ponencia o un libro; los reportes policiales y las formas cómo se presentan las notas informativas; o cómo se narran los sucesos en la vida cotidiana, por citar algunos casos. Todos estos textos, aunque de distintos géneros, tienen "prescripciones estrictas" para narrar y otorgar verosimilitud a lo que se intentan exponer, describir o explicar. De tal modo, hay ciertos contenidos y referencias que deben tener los libros, como la bibliografía o las notas a pie, y otros distintos se utilizan en los policiales, como los testimonios; de la misma manera, se omiten algunas cuestiones en los reportes científicos y en los noticiarios. Tales conforman las reglas de juego para las distintas formas narrativas. Existen diversas formas de decir y de presentar; en el caso de los reportes policiales y los noticiarios, pueden fincarse en rumores o imágenes; y en el de los libros o los reportes científicos, se basan en las hipótesis o en la argumentación lógica. En la vida cotidiana se permite cierto desorden, en cambio, el ámbito científico lo rehúye.

Con base en esta tesitura, ampliar las posibilidades de elección de mediaciones en determinadas situaciones se ha nombrado como "concepción optimista de la cultura", a saber, plantea que los grupos tienen "un grado de elección" de los medios a utilizar cuando realizan una actividad. De esta manera, en el juego de herramientas, "un grupo se acerca al entorno de una tarea que requiere una función mental (por ejemplo, la memoria) de una manera tal que cuenta, por lo menos en principio, con múltiples opciones diferentes para tratar con ella" (Wertsch, 1997, p. 185). Hay "fuerzas" que dan forma a ese uso, y son sociohistóricas. Un ejemplo que puede reafirmar lo anterior es el de las estrategias que se usan para recordar. El caso es el de un infante de seis años que ha extraviado un juguete y solicita ayuda a su papá. "El padre pregunta dónde lo vio por última vez; la niña dice 'no puedo recordar'. Él hace una serie de preguntas: ‘'lo tenías en tu habitación?, ¿afuera?, ¿al lado?’, ante cada pregunta la niña responde 'no'. Cuando él dice ‘en el coche?', ella responde 'creo que sí', y va a recuperar el juguete" (Tharp \& Gallimore, en Wertsch, 1991, p. 45). La interrogante aquí es, quién recordó: la niña o el papá. La respuesta es, los dos: y las formas o estrategias para recordar serán utilizadas por la niña con el paso del tiempo, pero tales estrategias tienen su origen en el plano social, en la relación con su padre y de éste con la cultura donde se encuentra inmerso. Se va de lo intermental a lo intramental, de lo cultural a lo personal. Ya que las actividades prácticas se realizan con ayuda o están guiadas por el lenguaje y el intercambio, podemos hablar del diálogo.

\section{La base del intercambio: el diálogo}

La unidad de análisis o de trabajo para Vygotsky (1932) y su escuela era la díada o la acción mediada. Para Mijail Bajtín (1979) la unidad de análisis era el enunciado, en tanto que 
es "la verdadera unidad de la comunicación". Desde ahí se posiciona, "el habla puede existir realmente sólo en la forma de enunciados concretos de hablantes individuales, sujetos del habla. El habla está siempre moldeada en la forma de un enunciado que pertenece a un determinado sujeto hablante, y fuera de esta forma no puede existir" (en Wertsch, 1991, p. 69, cursivas en el original).

En su momento Bajtín también habló de "translinguística", que sería el equivalente de lo que ahora se conoce como "pragmática" o "análisis del discurso", si incluyeran su noción de "voz" y "dialogicidad". La voz, esa palabra emitida, ese discurso pronunciado, esa narrativa expresada, ligada al enunciado, es quien habla, conciencia incluida: tono, contexto, intención, visión del mundo, punto de vista, y aplica tanto para la comunicación oral como para la escrita. Tal voz, que debería decirse voces, se encuentra inscrita en un medio social, al menos la voz del que habla y la voz de aquel al que se le dirige; encontramos, entonces, una vinculación entre las voces. Cuando dos voces o más entran en contacto, se vinculan, se presenta la significación; antes no la hay. Se da cuando se presenta la "direccionalidad", dirigirse hacia el otro. En consecuencia, cuando una palabra, oración o voz se orienta hacia alguien, hacia otra voz, se tiene un "enunciado completo". Y en la cadena de la comunicación verbal, el enunciado es una pieza (Wertsch, 1991). Los enunciados son, en sentido estricto, también respuestas a otros enunciados, pensados y expresados, y llegan a ser en diver- sas ocasiones contraargumentos a determinados argumentos planteados, tipo retórica de los griegos (Billig, 1987).

La voz que se expresa puede tener interlocutor físicamente presente, público, audiencia, imaginada o real, en el presente o en el futuro, que bien puede ser el caso de las biografías o de ciertos textos pensados para próximas generaciones. En tal caso, el enunciado da cuenta no únicamente de quien enuncia, sino de a quién se responde, por el tipo de respuesta que se da a otro enunciado. Se sabe en qué tono o de qué manera responder si es pregunta, ofensa, afirmación, etcétera. No es el mismo tipo de respuesta que se ofrece ante una pregunta esgrimida en una sobremesa, que la enunciada en un congreso académico o en una clase. En este caso, existe interés en quien produce un enunciado o discurso y en a quién se dirige, es decir, la direccionalidad. Los enunciados involucran al menos dos voces, lo que da paso al diálogo. El diálogo es una de las categorías de mayor relevancia en el ámbito de la comunicación (Bajtín, 1979).

En ese sentido, un presupuesto para los enunciados y las voces es el constructo bajtiano de dialogicidad. Dice Bajtín que "el enunciado está lleno de armónicos dialógicos" (en Wertsch, 1991, p. 73, cursivas en el original). Al respecto, otro autor de esta escuela, Valentín Voloshinov (1929, p. 142, cursivas en el original) dirá: "comprender un enunciado ajeno significa orientarse respecto de él, encontrarle un lugar apropiado en un contexto correspondiente", así, 
"por encima de cada palabra de un enunciado que vamos entendiendo formamos una especie de estratos formados con nuestras propias palabras de respuesta", en consecuencia, "cuanto mayor es su número y cuanto más importantes son, tanto más profunda y sustancial es la comprensión". En ese sentido, "toda comprensión es dialógica". La dialogicidad es intercambio de voces y enunciados, que se animan uno a otro y se da, sobre todo, en la comunicación verbal directa cara a cara; ahí se presenta la comprensión (Bajtín, 1979, 2000).

Un diálogo es sobre todo alteridad, juego de relaciones sociales entre alguien que habla y otros que escuchan o igualmente hablan. Hablamos y realizamos una acción mediada, en este caso por una herramienta: el lenguaje, los signos. Dichos signos inician, en lo aquí suscrito, por la palabra: "las unidades del discurso interno son ciertas totalidades que en algo recuerdan los párrafos del discurso fonológico o bien enunciados enteros", no obstante, "lo que más traen a la memoria son las réplicas de un diálogo. Por algo el lenguaje interno fue conceptualizado ya por los pensadores más antiguos como un diálogo interno" (Voloshinov, 1929, p. 66, cursivas en el original). A eso se le denomina llanamente pensamiento (Mead, 1934). Quizá por ello Vygotsky (1934) se interesaba en el estudio del habla, para dar con el pensamiento y la conciencia, al respecto dirá: “el estudio del pensamiento y el lenguaje es una de las áreas de la psicología en que es particularmente importante una com- prensión clara de la relación entre las diversas funciones psíquicas" (p. 49).

Así, el autor plantea el origen social de la actividad mental de las personas. Lo que en algún momento se señaló como actividad individual, este autor le otorgó una interpretación cultural. La actividad mental tiene vida en un entramado social, en un marco cultural; hay relaciones sociales internalizadas, es el caso del lenguaje, el pensamiento y la conciencia: "la dimensión social de la conciencia es primaria en el tiempo y en los hechos. La dimensión individual de la conciencia es derivativa y secundaria" (en Wertsch, 1991, p. 30). En el caso de Bajtín y su escuela no será distinto, y en ese sentido, la conciencia denominada personal es conciencia dialógica, porque está mediada por el lenguaje, por los signos, toda vez que están presentes otras narraciones, voces o conciencias a las cuales nos dirigimos o escuchamos. El fenómeno del dialogismo oculto, distinto de la polémica oculta, es relevante en los siguientes términos: Imaginémonos un diálogo de dos en el que las réplicas del segundo interlocutor se omiten de tal manera que el sentido general no se altera. El segundo interlocutor está presente invisiblemente, sus palabras no se oyen, pero su huella profunda determina por completo el discurso del primer interlocutor. A pesar de que sólo habla una persona sentimos que se trata de una conversación, y una conversación muy enérgica, puesto que cada palabra presente reacciona entrañablemente al 
interlocutor invisible, señalando fuera de sí misma, más allá de sus confines, hacia la palabra ajena no pronunciada. (Bajtín, 1979, pp. 287-288).

Efectivamente, en torno a lo que decimos, la mitad de lo dicho alguien más lo ha enunciado o proviene de ese alguien; hablamos dirigiéndonos a alguien más o respondiendo a alguien más. El enunciado es, en este caso, una unidad concreta de la comunicación verbal, y lo es en una relación en un contexto extraverbal, y tal contexto forma parte del enunciado conformando su sentido y estructura. Igual que ocurre en Vygotsky, para Bajtín el lenguaje es una práctica social. Piénsese en la forma antigua de los coloquios: el simposio era un diálogo festivo (Bajtín, 1979).

El diálogo es el mecanismo donde lo social se incorpora a la conciencia y al texto. Nuevamente, de relevancia es la palabra en Vygotsky (1934) y el enunciado en Bajtín (1979), ahí se encuentra el sentido, como unidad comunicativa surge ahí el sentido: "el acto de enunciar consiste en el pasaje del pensamiento o del lenguaje interior a la expresión verbal, al enunciado real, y por lo tanto -así definida- la enunciación es una categoría psicololigüística" (Silvestri \& Blanck, 1993, p. 49). Y eso que se piensa debe exteriorizarse; lo que sé, veo, siento, quiero y amo, no se atraviesa por la línea de la comprensión, "sólo lo que todos los hablantes sabemos, vemos, amamos y admitimos, aquello en lo que todos estamos de acuerdo, puede volverse parte sobreentendida del enunciado" (Bajtín citado en Silvestri \& Blanck, 1993, p. 50). Luego en- tonces, el contexto de Bajtín es un horizonte temporal y espacial, y la comunidad a la cual se inscriben los hablantes, contexto social, pues el sentido que le otorga la gente a ciertas palabras viene dado por el contexto social y cultural. Los hablantes tienen ciertas adscripciones: edad, sexo, familia, profesión, ciudad, etcétera; comparten contextos, se acompañan de una determinada cultura.

Ahora bien, si el signo "refleja" de cierto modo la realidad, se impacta de una visión de la realidad cargada de ideología, en ese caso el signo es también ideológico, comunica cierta carga de ideología, es decir, se interpreta esa realidad que se dice refleja el signo, y se interpreta en el intercambio comunicativo. Se comunica ideología. En ese tenor, un enunciado tiene significado y signo, signo que posee una orientación valorativa. Los signos vehiculizan ideas sobre la realidad que anuncian, y muchas de esas ideas vienen con carga ideológica, ello porque las expresiones surgen en un contexto socio-histórico y político y llegan a expresar el punto de vista de un grupo social en particular. Puede pensarse en la palabra "indio" o "negro", que designan en sociedades sometidas $\mathrm{O}$ colonizadas un ámbito de menosprecio o sumisión. Siguiendo a Bajtín, Silvestri y Blanck (1993, p. 56) señalan: "cuando incorporo a mi conciencia un signo, lo incorporo ya empapado con la valoración social, con el punto de vista de un grupo determinado, aun cuando no necesariamente pertenezca a ese grupo" o "ya se hayan extinguido las circunstancias objetivas 
que generaron dicha valoración". Ahora bien, es cierto que en un signo, en una misma palabra, puede manifestarse un entrecruce de sentidos: no es el mismo sentido que tiene la palabra "negro" entre afros que entre una comunidad de blancos; o la palabra "indio" para aquellos que reivindican los derechos de los pueblos originarios o para una empresa trasnacional sin interés en los derechos de los habitantes originales. El mismo caso se presenta para el sentido de la palabra "burgués" en Occidente o en un ámbito socialista (Bajtín, 2000), o la palabra "burro" en el ámbito escolar.

Por lo demás, en esta perspectiva, la ideología no es la falsa conciencia, al estilo de la ortodoxia marxista, sino un sistema de ideas socialmente determinadas, una especie de sistema de valores y perspectivas sociales. Puede, asimismo, hablarse de ideología cotidiana: "todo el complejo de las sensaciones cotidianas -aquellas que reflejan y refractan la realidad social objetiva- y las expresiones exteriores inmediatamente ligadas a ellas" (citado en Silvestri \& Blanck, 1993, p. 58). Hay ideología o signos ideológicos. Un ambiente ideológico estaría poblado por signos ideológicos diversos, lo mismo de religión, filosofía, arte, ciencia, cotidianos, que es en donde finalmente nos encontramos día a día. La realidad se presenta ante nuestra conciencia en ciertos momentos históricos, y en momentos determinados, algunos objetos y propiedades cobran interés en la atención de ciertos grupos. Tales objetos se impregnan de significado y de ideología, y se vuelcan al intercambio comunicativo. Ello también nos va constituyendo, la acción comunicativa, la mediación de la acción.

Para hablar de acción mediada, retomando la noción de "acción comunicativa" de Jurgen Habermas, Wertsch (1991) postula la interacción de al menos dos personas, una díada, que habla y actúa, que se relaciona verbal o extraverbalmente. Tratan estas dos personas de comprender la situación donde actúan, hablan y dan cuenta de sus planes para poder así coordinar sus acciones mediante un acuerdo. La interpretación en este caso es clave, pues lleva consigo la negociación de la situación y cómo se ha de comprender mutuamente. En este marco podemos incluir el contexto.

\section{Lo dicho en contexto y lo enunciado en descontexto}

La función primaria del habla y del diálogo es la comunicación. Dicha comunicación se presenta en un contexto determinado, en condiciones particulares. La palabra "gallo" cobra su sentido en el contexto de una frase y de una situación: "vamos a dar gallo", en una situación de romance y relación, cobra su sentido de serenata; "voy a comprar un gallo", en una situación de ponchadura de llanta tiene el sentido de llanta de refacción; "se cree muy gallo", en una situación de pleito, tiene sentido de valiente; "trae la comida para el gallo", en un contexto de campo se refiere al animal.

Bien. Ahí está el contexto: frase, situación, enunciado, dirá Bajtín. Y de eso ha tratado más o menos hasta aquí el presente trabajo. 
Que a su vez es de lo que trata, inicialmente, el lenguaje. Al asumir una visión filogenética, podemos afirmar que "el lenguaje surgió en el proceso del trabajo, en la empresa encarada grupalmente y la comunicación engendrada por ésta", y "los primeros signos tenían un carácter totalmente simpráxico: su significación era inseparable de la situación concreta en que se encontraban. No tenían significado" (Silvestri \& Blanck, 1993, p. 61, cursivas en el original). Se encontraban en un contexto empírico, no estaban descontextualizados. Después se estabilizaron, se endurecieron los referentes de las cosas más relevantes para los grupos, se fijaron. Por eso ahora hay que ir del otro lado, al descontexto, ahí donde no hay referencia empírica o experiencial. Ese es el proceso social que sigue.

Los signos denominados conceptos van de la contextualización a la descontextualización. La palabra ideología es introducida por Antoine Destut de Tracy en 1801, quien la refirió como “el análisis de las sensaciones y las ideas". No es que él la haya inventado, como suele hablarse individualistamente de la creación de los genios, más bien permeaba en el ambiente de ciertos grupos de la época, aquellos que le otorgaban un rango superior a la razón y no a los prejuicios, a lo divino o a la superstición. El grupo de que participaba analizaba las ideas, y en ese contexto sociohistórico surge la expresión de ese signo alrededor de una idea. Los iluministas, de los primeros en usarla, lo hacen en beligerancia contra los poderes feudales. Tiene un tipo de valoración en ese contexto. De tal modo, en la época napoleónica tiene otro valor el mismo signo, otro sentido, pues el conflicto de los poderes imperiales con los "ideólogos" era frontal, por consiguiente, el signo cobra una factura negativa, y así por caso Napoleón los acusa de no tener contacto con la realidad (Abbagnano, 1961). Con el cambio de sentido, de contexto a descontexto se va trazando la idea. Esa es una manera, como la idea de enajenación en Marx (1932, pp. 42-44), esa denominada desvinculación en el proceso de producción. Tal desvinculación es punto central. Otra forma puede presentarse al ir del diálogo al monólogo. Sobre el diálogo Lev Yakubinskii dirá:

De acuerdo con una forma de interacción humana directa ('cara a cara'), tenemos formas de interacción verbal directas que se caracterizan por una percepción visual y auditiva directa del interlocutor. De acuerdo con la interacción indirecta o mediada, tenemos el área del habla, por ejemplo, una forma de expresión escrita. De acuerdo con formas alternativas de interacción que implican una sucesión relativamente rápida de acciones y reacciones por parte de los interlocutores, tenemos una forma dialogada de interacción social verbal; de acuerdo con las formas de influencia prolongadas o interminables en la interacción social, tenemos una forma monologada de expresión verbal. (citado en Wertsch, 1988, p. 102, cursivas en el original). 
Esta larga cita puede clarificarse si se considera que el diálogo es anterior y más "natural"; el monólogo es una forma más complicada, en ocasiones superior y posterior, que se puede manifestar en el lenguaje escrito, por ejemplo. En el diálogo cotidiano se es menos explícito que en el monólogo; esa necesidad de explicar al máximo las formulaciones lingüísticas en el monólogo escrito surge no sólo por la ausencia de intercambio verbal que permita abreviaciones compartidas en situaciones conocidas, sino también por la ausencia de un contexto comunicativo compartido por el lector. A manera de ilustración: 1) en un salón de clase no hay un contexto comunicativo adecuado para que se dialogue un escrito académico; 2) en un salón de clases hay un monólogo, en el sentido de Yakubinskii, toda vez que se necesita explicitar mucho más que en un diálogo o conversación cotidiana. De ahí el reconocimiento de un elemento en la falta de entendimiento y comprensión.

Conocimiento o masa apercibida decía Yakubinskii: cuanto más tienen en común los hablantes en un intercambio o diálogo, más fácilmente comprendemos y percibimos su habla en la conversación, además, el habla de nuestro interlocutor puede ser incompleta pero abunda en pistas, señales, signos que el contexto y la cultura proporciona. Donde se comparten códigos, formas, tonos, voces, pensamientos, lo explícito es menos probable, menos manifiesta: "si todo lo que queremos expresar estuviera contenido en los significados formales de las palabras que usamos, tendríamos que usar muchas más palabras de las que en realidad usamos para expresar cualquier pensamiento", puesto que "hablamos únicamente mediante el uso de las claves necesarias" (Yakubinskii, citado en Wertsch, 1988, pp. 102-103). Esto lo reconoció Vygotsky (1934), al señalar que autores como Yakubinskii y Polivanov pusieron acento en la "percepción compartida", visión del mundo, de las partes que se comunicaban, lo cual era una necesidad para el diálogo cotidiano. El diálogo formal requiere más palabras de las que usamos ordinariamente para charlar con nuestros semejantes. De esta suerte concluía, "es natural que hablemos por insinuaciones" (p. 217).

Por otro lado, el lenguaje puede usarse en el pensamiento abstracto de una manera descontextualizada, pues el desarrollo conceptual es una forma de descontextualización. Cuando Jerome Bruner (1997) expresa que la cultura nos dota de instrumentos para organizar y entender nuestro mundo de manera comunicable, está hablando, entre otras cosas, del lenguaje, del significado como base para el intercambio, y la mente se apoya en sistemas simbólicos de un entramado cultural. En medio se encuentra el lenguaje, que denomina "referente a distancia", toda vez que no requiere de lo concreto de la experiencia ni del contexto para dar cuenta de lo que se intenta comunicar, por ejemplo, la Independencia o la Revolución mexicana; no hay que estar en situación bélica para comprender dichos eventos, ni tampoco haber atravesado por ella. Hay un significado que la cruza y eso se 
comprende. Somos la única especie que enseña de manera significativa, y eso va configurando el pensamiento, la mente. Pues bien, la vida mental se forma y vive en común y se conforma con la ayuda de códigos culturales, tradiciones, normas, etcétera. No obstante, hay algo que denominamos pensamiento abstracto, alejado de lo concreto, y ese no requiere contexto; a eso más bien se le denomina descontextualización. En psicología social Henri Tajfel (1981) le nombra "categorización social", ese proceso de unificación de personas, objetos o sucesos sociales en grupos o categorías que conforman las creencias y el pensamiento social, es ésta una manera de la generalización. Otra manera se denomina silogismo, otra más razonamiento científico. En sí, son diversas maneras de la descontextualización.

Todo lo anterior no es protervo, si se piensa que, como hemos venido diciendo, la palabra y el diálogo tienen una direccionalidad hacia la comunicación. Pues bien, "la verdadera comunicación requiere significado (generalización), tanto como signos". Cierto, si se quiere dar cuenta de la experiencia o el pensamiento de uno ...es obligatorio relacionarlos con alguna clase o grupo conocido de fenómenos. Tal referencia, sin embargo, requiere ya la generalización. Por tanto, la comunicación presupone la generalización y el desarrollo del significado de las palabras; así pues, la generalización se hace posible en el curso de la comunicación. Las formas superiores, específicamente humanas, de comunicación psicológica son posibles porque el hombre refleja la realidad a través de conceptos generalizados. (Vygotsky, 1934, p. 53).

El ser humano realiza actividades en el plano inmediato y contextual, pero puede hacerlo asimismo en planos más abstractos, desvinculados. Las herramientas posibilitan que eso suceda. De hecho, cuando la gente fábrica herramientas lo hace con un fin, para algo, la atención y la conciencia se encuentran, entonces, en otro ámbito o dirigido hacia un fin, un cambio en la casa, escuela o escenario por ejemplo, es llevado a cabo haciendo uso de herramientas. Tal utilización es un acto de mediación, pues son instrumentos para que la acción de la gente se dirija hacia otra cosa, como solucionar un problema, lo cual implica una ruptura con lo inmediato y el contexto de acción.

La descontextualización de los instrumentos de mediación juega un papel relevante, en especial si se piensa en cómo trata lo histórico-social y la ontogénesis: "esta forma de descontextualización es posible a causa de uno de los elementos potenciales latentes en el lenguaje: el potencial de los tipos de signos y de sus relaciones sistemáticas para ser utilizados como elementos de reflejo" (Wertsch, 1988, p. 225). En la escolarización, se pueden ver manifestaciones de la descontextualización, como ocurre con los estilos discursivos $\mathrm{y}$ procesos sociocognitivos que se encuentran atravesados por los instrumentos de mediación. 
Para ahondar en la falta de contexto en la comunicación, hay que traer a colación lo que señala Umberto Eco (2000), a saber, una expresión no designa un objeto en particular sino que transmite contenidos culturales, no referentes sino ideas, no lo concreto y particular, como otros autores señalan. Consideran necesario "liberar al término 'referente' de toda clase de hipotecas referenciales" (citado en Silvestri \& Blanck, 1993, p. 45). Luego entonces, esta descontextualización puede llevar a la clase de género, ciertas abstracciones y generalizaciones, cosa que para otros semióticos no es viable porque imposibilita la comprensión y el diálogo. Pero ahí hay ya descontextualización que se manifiesta, por ejemplo, en el ámbito de la educación.

\section{Construcción social del conocimiento}

En la misma línea argumentativa, para varios autores de esta escuela sociohistórica, las narrativas que usan las personas en situaciones concretas son relevantes. Los distintos grupos sociales tienen un acceso, sino ilimitado sí amplio en las arenas del lenguaje, de los discursos, para construir su realidad y dar cuenta de ella. Los construccionistas sociales (Gergen, 1994) saben al respecto, sobre todo, cuando indican que las distintas formas de hablar dependen del mundo en la medida en que aquello que se dice se encuentra "enraizado, o basado, en lo que los hechos del mundo" permiten decir; asimismo, lo que se toma como naturaleza del mundo "depende de nuestras formas de hablar de él".
En tal caso:

No es sólo que se pueda decir que ambas cosas son ciertas, sino que se deben afirmar las dos, pues deben su existencia separada a su interdependencia... si bien se debe decir sobre las circunstancias sólo lo que los hechos permitan, la naturaleza de tales hechos es tal que permite afirmar dos verdades opuestas. (Shotter, 1990, p. 142, cursivas en el original).

Como ocurría con los retóricos griegos del siglo V a. C., cuando existían dos puntos de vista igualmente válidos ante una situación, como bien esgrimía ese gran retor y hacedor de frases, Protágoras (Billig, 1987).

En la vida cotidiana se busca la comprensión mutua y se comparte saber. En la vida cotidiana si queremos entender el sentido de lo que se habla en una conversación hay que tener una idea de lo que se quiere decir, y para ello hay que estar inmersos en un marco común, proporcionado por la cultura y los grupos a los cuales adscribimos. De tal forma se puede saber qué esperan las personas con sus transacciones lingüísticas. En efecto, el lenguaje coordina la acción humana; "hablado y escrito, representa el modo de coordinación más rico en matices, más sofisticado y con mayores potencialidades múltiples, que tenemos a nuestra disposición para el desarrollo de las relaciones, la cultura, y una sociedad viable", además, "representa uno de los medios principales de producción de significados, mediante el cual se articula y se 
evalúa el mundo. Es mediante el lenguaje que alcanzamos a ser construidos como ser humanos" (Gergen, 2015, p. 68). La cultura como marco mayor nos suministra guías para saber cómo comportarnos en ciertas condiciones, qué decir, cómo decirlo, y también nos da indicaciones sobre la enseñanza y el aprendizaje. Lo ha dicho Jerome Bruner (1997), la educación, la práctica educativa, se despliega en un marco mayor, en la cultura, y con cierta ideología de reproducción que, como ya vimos, atraviesa los signos.

En efecto, nuestra habla o las acciones que realizamos están inscritas en escenarios sociales, socioculturales, sociohistóricos, de tradiciones y normas que la sociedad nos provee. Pero no es homogénea la manera de hacerlo, claro está. Hay diversidad, hay multiplicidad, existen grupos, hay comunidades de hablantes; las personas pertenecen a una o varias de estas comunidades. El lenguaje social es usado por distintos grupos a su manera, sacerdotes, académicos, abogados, literatos, etcétera, que tienen una variante del lenguaje, del idioma que a todos atraviesa, y hacen uso de ciertas maneras y ciertas palabras así como de determinadas narrativas, perspectivas al fin y al cabo. Más aún, Wertsch (1997) afirma que los grupos tienen acceso a "más de un lenguaje cuando describen y explican tanto sus propias pautas de comportamiento y pensamiento como las de los demás" (p. 186). Con esas descripciones del mundo, con su lenguaje de por medio, llegan, por ejemplo, a la escuela. Y aquí encontramos un ámbito de investigación educativa.

\section{El aula: compartir conocimiento}

¿Por qué a algunos estudiantes, desde primaria hasta universidad, se les complica la comprensión de los discursos en un salón de clases? Desde los años setenta del pasado siglo $\mathrm{XX}$, se viene trabajando sobre la respuesta a esta cuestión. Se sabe, por ejemplo, que los estudiantes provienen de distintas comunidades de lenguaje, esto es, que pertenecen a grupos disímiles, aunque vivan en la misma ciudad o demarcación. Así, aquellos que provienen de comunidades, ya sea familia, amigos o barrio, donde los discursos y las narrativas tienen poco o nada que ver con los discursos o las narrativas científicas que se expresan en los libros o en el salón de clase, tendrán mayor complicación para la comprensión de este tipo de conocimiento. El lenguaje de la calle es uno y el del salón de clase es otro, el de casa es uno y el de la ciencia es otro. Los discursos de casa se hacen, sobre todo, con palabras, los discursos de la ciencia se hacen con conceptos. Por eso, en muchos casos, el lenguaje que tenemos en casa o con los amigos tiene poco relación con el lenguaje de los libros de psicología, psicología educativa o psicología social, por ejemplo, en los cuales se habla de minorías activas, de "yo, mí, me”, de disonancia cognoscitiva, de psicología colectiva, de representaciones sociales, de zona de desarrollo próximo, de andamiaje, de interpensar, etcétera. De ahí la recurrencia al ejemplo, la analogía, la metáfora, para poder explicar de qué se está hablando. 
En no pocos casos, uno se encuentra con estudiantes a quienes les cuesta mucho trabajo comprender una lectura que aparentemente es elemental o básica. Las complicaciones son muchas, es un río de términos revuelto. Con frecuencia encontramos alumnos que desconocen el significado de ubicuidad, etimología, epistemología, hermenéutica, signo, andamiaje, alter, univocidad, etcétera. Si a los estudiantes de licenciatura se les dificulta este andar en el lenguaje, habrá que pensar en los infantes ante un mundo de significados mediado por las palabras y los conceptos.

Así lo hace un grupo de trabajo de la escuela de Loughborough, Inglaterra, donde se encuentran Derek Edwards y Neil Mercer, quienes con base en autores de la tradición vygotskyana, realizan estudios sobre el lenguaje, el pensamiento y el conocimiento escolar. Parten de un supuesto que señala Vygotsky (1932, p. 49): "los niños resuelven tareas prácticas con la ayuda de su habla, igual que con los ojos y con las manos". Ciertamente, "el lenguaje es un instrumento de apoyo para la ejecución práctica, mirar el mundo, comprenderlo y enfrentar dificultades" (Medina, 2007). Con lenguaje se piensa, con lenguaje se instruye para resolver problemas, con lenguaje se crea conocimiento y con lenguaje se comparte. Con lenguaje interpensamos (intermental), pues si al esgrimir una buena argumentación alguien cambia de opinión, con buen discurso se edifican y comparten conocimientos. El lenguaje como condición de posibilidad y en ese sentido el conocimiento como producción social (Flores,
Íñiguez, \& Martínez, 2015, en consecuencia, durante la educación se tendrían que enseñar estrategias lingüísticas eficaces para pensar conjuntamente y por separado a los estudiantes.

Desde la perspectiva vygotskyana, "una verdadera comunicación, entendida como intercambio de signos, sólo puede manifestarse cuando los participantes del intercambio comparten un sistema convencional, es decir, simbólico" (Medina, 2007, p. 66). En tanto que la educación bien puede ser vista como un proceso comunicativo, habrá que hurgar cómo se presenta en un ámbito de educación formal, es decir, de institución educativa; hay que explorar cómo se recibe, cómo se comparte e incluso cómo se controla, cómo se discute, cómo se comprende y cómo se mal comprende o mal interpreta, el conocimiento en clase. Se necesita hurgar el significado del conocimiento para aquel que estudia y para aquel que imparte clases, explorar cómo comprenden conjuntamente la realidad. Necesitamos indagar si hay base mutua de comprensión y de conocimientos. Compartir conocimiento implica, asimismo, que los aprendices aprendan, valga la redundancia a ver el mundo desde nuevas perspectivas, antes no contempladas. Compartir conocimiento conlleva que "dos personas saben ahora lo que antes sabía sólo una... cuando dos personas se comunican, existe realmente la posibilidad de que, reuniendo sus experiencias, lleguen a un nuevo nivel de comprensión más alto que el que poseían antes" (Edwards \& Mercer, 2000, p. 15). Son las relaciones con personas 
más capaces, como un maestro, por ejemplo, las que posibilitan y favorecen un desarrollo y aprendizaje más allá del nivel actual (Medina, 2007).

En esta perspectiva se habla de negociación en el aula, de sopesar los significados de las palabras académicas (conceptos) con las palabras cotidianas (palabras). Su base se encuentra en lo que se ha denominado descontextualización, al hablar de "descontextualización de los instrumentos mediadores", esto es, que las palabras o unidades lingüísticas se abstraen del contexto comunicativo en que se han empleado originalmente. Tal es el caso de los conceptos académicos o científicos, que tienen una definición y una cierta rigidez, casi opuestas a la lógica de las palabras cotidianas, flexibles, que se ligan a la experiencia o al mundo conocido. En el caso de los conceptos, la relevancia estriba en la relación que mantienen con otros conceptos, además, se presenta una cierta independencia extralingüística; en el caso de las palabras cotidianas, lo que resulta significativo es la relación que esas palabras tienen con la experiencia concreta (Wertsch, 1991, p. 56).

Los significados de los conceptos varían poco, más bien permanecen en distintos contextos discursivos, como ocurre con las definiciones de los diccionarios. La palabra otorrinolaringólogo, ese médico que trata enfermedades del oído, nariz y laringe, se mantiene independientemente del contexto. No ocurre así con la palabra gallo, de uso cotidiano y de sentido disímil, dependiendo del contexto, como ya se ha visto líneas atrás. Efectivamente, entramos al terreno del sentido y el significado, del cual Vygotsky (1934) dirá:

El sentido de una palabra es la suma de todos los acontecimientos psicológicos que la palabra suscita en nuestra conciencia. Es todo un complejo, fluido y dinámico, que tiene varias zonas de estabilidad desigual. El significado es sólo una de las zonas del sentido, la zona más estable y precisa. Una palabra adquiere su sentido a partir del contexto en que aparece; en diferentes contextos cambia su sentido. El significado se mantiene estable en los cambios de sentido. El significado que el diccionario da de una palabra no es más que una piedra del edificio del sentido, tan sólo una potencialidad que encuentra en el habla una realización diversificada. (p. 222).

Contextualizado así, hay que entender la direccionalidad de la negociación: resaltar que tanto académicos como estudiantes recurren al ejemplo, la analogía y la metáfora para entender el significado a partir del sentido. En el caso del conocimiento académico, se trata de transitar sobre la base de la experiencia y de las palabras que lleva el estudiante hacia el uso y manejo de términos técnicos, es decir, conceptos.

El habla, el discurso en el aula, no siempre ha sido un tema de interés para quienes estudian distintos ámbitos de la educación. Puede hablarse de cierta ausencia del análisis del discurso, del habla, de la conversación, de la narración en el 
aula, hasta hace poco tiempo. Dar cuenta de las conversaciones en el aula, ahora lo sabemos, es sumamente relevante. Analizando el discurso y la conversación en el aula se puede dar cuenta de, por ejemplo, cómo el orden del discurso en una clase es parte de un orden formal más amplio, pertenece a una estructuración del habla que determina cómo se discurre el conocimiento. Analizar formas discursivas y conversacionales en el aula nos permite adentrarnos en, por ejemplo, otras más comunicacionales de educación y de formación. En la educación importa analizar el discurso y la conversación, su forma, su contenido, lo que se dice, cómo se dice, de qué se habla, qué palabras se usan, así como analizar los marcos no lingüísticos que devienen contextos para el discurso. Se trata de investigar las continuidades del habla y las experiencias compartidas. No obstante, debemos considerar que para analizar lo dicho en el aula, quien registra la comunicación debe ser capaz de interpretar la charla, entender el sentido de lo que los hablantes quieren comunicar, tener un marco común.

Hay interacción social en la vida cotidiana y en el salón de clase. Muchas de las formas de habla en el salón de clase son fórmulas que se usan fuera del mismo, tienen propiedades comunes, tienen lo que se denomina reglas básicas. Tales reglas básicas aluden a los elementos de comprensión que las personas tienen para participar en una conversación, para así dar sentido a lo que escuchan o dicen, por ejemplo, el principio de cooperación, con sus máximas tales como la calidad, o bien, que se digan cosas ciertas; la cantidad, brindar información; la relevancia; y el modo, ser claro.

Así como hay reglas, hay contexto o marco social donde se despliega la conversación cotidiana y de ahí se toman pautas. La clase es un marco social en el cual se posibilita cierto intercambio de signos. Los tribunales tienen su propio marco de referencia por el cual discurren ciertos contenidos y estructuras discursivas. Los hospitales son otro ejemplo. La escuela tiene sus formas: en una clase hay tres tipos de comprensiones o guiones a considerar: 1) el maestro hace las preguntas; 2) el maestro conoce las respuestas; 3) repetir la pregunta supone error en las respuestas. Además, el maestro habla más y el maestro pregunta más. Preguntar suele ser un mecanismo de control, el maestro pregunta para saber si se le está poniendo atención y checar si están aprendiendo o saben de lo que se habla. En sentido estricto, la mayor parte de las preguntas que realizan los profesores no busca información, más bien, "forman parte del armamento discursivo de que disponen los maestros para controlar temas de discusión, dirigir el pensamiento y acción de los alumnos y establecer los límites de la atención compartida, de la actividad conjunta y del conocimiento común" (Edwards \& Mercer, 2000, p. 62). Si un alumno pregunta algo y el maestro no hace caso es que no formaba parte del guión o de la agenda para la clase; el maestro controla la clase y sabe de qué se hablará y de qué no. 
Por tanto, debemos explorar menos las estructuras lingüísticas en sí y más las relaciones entre el discurso y lo que se comparte como conocimiento, es decir, su contenido (de qué se habla), los involucrados (quién habla a quién), para dar cuenta del submundo o microcosmos o subcultura y, por consiguiente, del orden social que ahí se manifiesta. Existen varias razones para intentar este tipo de acercamiento, como retomar o exponer lo que se ha señalado en distintos momentos; en múltiples casos, la interacción discursiva en el salón de clase está organizada para una transmisión controlada del conocimiento. $\mathrm{O}$ bien, en el discurso dentro del aula los entendimientos se presentan en un marco o una relación de poder entre maestro y alumnos. El maestro trae consigo una ideología, puede ser una dominante, y los alumnos deben aceptar esa cultura o ideología, así como el conocimiento y las prácticas que de ella se derivan. Otra razón es la que procede del razonamiento de Anthony Giddens:

El análisis del discurso en clase posibilita el mostrar a nivel 'local' que 'las estructuras sociales están constituidas por la actuación humana $\mathrm{y}$, al mismo tiempo, son el medio mismo de esa constitución', y tal vez mostrar también que los niños de clase media tienen mayor acceso a formas 'privilegiadas' de discurso. (citados en Edwards \& Mercer, 2000, p. 29).

Se trata de ubicar la información dada y la información nueva; lo que ya se trae y lo que se edifica en ese momento:
Hay realmente mecanismos lingüísticos, utilizados en la presentación de información bien como dada, bien como nueva, pero estos mecanismos no se basan simplemente en lo que los hablantes y oyentes saben realmente, ni siquiera en lo que uno supone que sabe del otro. Se trata más bien de un mecanismo del que se dispone para utilizar en la construcción de un conocimiento compartido, en el acuerdo y en el desacuerdo, en la persuasión y en la retórica, o en cualesquiera otros objetivos que puedan tener los hablantes al decir lo que hacen. (Edwards \& Mercer, 2000, p. 27).

El conocimiento compartido asume que existen otras maneras de edificación del conocimiento, como las prácticas sociales, las percepciones, los grafos, diversas formas de interacción social (la conversación es una entre tantas), no obstante, esta perspectiva pone especial acento en las transacciones conversacionales, en eso que se dice, se enuncia en el aula, para mirar desde otra perspectiva. Al hacer uso de otras categorías, de otros conceptos o términos vamos ligando otras maneras de mirar el mundo, una forma distinta de conocer, en especial con los relatos de orden conceptual de los libros que se usan en un aula universitaria, por ejemplo, "estas combinaciones de palabras señalan nexos y vínculos que con anterioridad no eran evidentes, entre las relaciones a las que fueron aplicadas" (Shotter, 2013, p. 85). El lenguaje edifica conocimiento. 
Ahora bien, recientemente se ha puesto cierto interés en el lenguaje como parte medular del compartir conocimiento, de hacer comprensible de manera conjunta lo que se enseña y aprende. Quizá no se ha hecho en demasía, pero hay trabajos varios que exploran los supuestos que arriba se han señalado. Aquí se presentan algunos. En un estudio, Candela (2010), desde una visión socio-cultural, analiza transcripciones de clases de termodinámica del tercer semestre de la carrera de física, entrevistas a alumnos y docentes, así como observaciones etnográficas de las prácticas de resolución de problemas y de otras actividades realizadas por los alumnos. Incorpora la perspectiva del actor-red, y se da cuenta de las estrategias que usa el profesor, sobre todo en cuanto a libros y artículos (artillería, le llama la autora), en una dinámica colaborativa donde se incluye a los estudiantes como actores en la construcción del conocimiento.

La necesidad de estudiar el aula desde una perspectiva interdisciplinar, pone atención en la cognición, la cultura y el lenguaje, a saber, la interacción entre profesor y alumno y sus discursos, tal lo plantean en su trabajo Candela, Rockwell y Coll (2009, p. 3). Se señala la importancia de abordar lo que se dice y no se dice en el aula con respecto al aprendizaje. Se convoca a registrar, transcribir y analizar no sólo una clase, sino un tema y un curso completo para tener un nivel macro sobre los discursos en el aula. En otro trabajo, Sánchez y Rosales (2005) hacen una revisión de las contribuciones de cuatro líneas de trabajo en el campo de la práctica educativa, una de las cuales es la desarrollada por Edwards y Mercer (2000). Los autores reconocen que ha tenido impacto y ha logrado poner en el terreno de la discusión la enseñanza como proceso comunicativo, donde profesor y alumnos colaboran para tener comprensiones conjuntas, esto es, se analiza cómo se utiliza el lenguaje para compartir conocimiento. Otro tanto se hace en el trabajo de Astudillo, Rivarosa y Ortiz (2008) desde el ámbito de las ciencias naturales.

Puesbien, laperspectivasocioconstruccionista es clave en la parte práctica del trabajo con discurso, dado que "al analizar las construcciones del discurso, focaliza la atención en el lugar donde se produce el discurso a partir de recursos lingüísticos preexistentes y muestran que solo se ponen en uso una parte de todos los recursos disponibles" (Flores et al., 2015, p. 202). E1 discurso se encuentra aquí orientado hacia la acción, privilegiando, no obstante, las prácticas lingüísticas sobre las no lingüísticas, como ya se enunció líneas atrás. Ahora bien, en el plano empírico, metodológico y de análisis, algunos de los ejes o categorías con los cuales se trabaja en la perspectiva de la construcción social del conocimiento, y que se anclan específicamente en el salón de clases serían los siguientes:

1. Ideologías. La práctica educativa tiene un contexto social, cultural e ideológico en el cual se desarrolla, y ello se puede mostrar en los contenidos de las conversaciones que en el salón de clase se manifiestan. La misma práctica educativa reproduce o cuestiona, según sean el momento y lugar, esa ideología contextual, los 
maestros expresan valores de la ideología en la cual están inmersos. Una puede ser la ideología que expresa el maestro, otra la que manifiestan los alumnos.

2. Discursos de poder y control. La ideología que trae consigo el maestro, los valores, las tendencias políticas, de alguna manera inclinan los discursos a interpretar de una manera, y no de otra, ciertos contenidos académicos. Por ejemplo, qué fechas reivindicar en el relato del pasado y qué omitir. Asimismo, en el caso de la comunicación en clase, los gestos y los silencios aportan pistas al respecto. De ahí la necesidad de grabar en video lo que en el salón de clase se comunica. Asimismo, el rol del maestro en la distribución de las participaciones es una manera de tener control en el grupo. El tipo de preguntas realizadas, los temas tratados, los temas que no se abordan. Distintas son las formas que cobra el control en un salón de clases.

3. Implícitos y explícitos. Hay supuestos en este rubro. Los maestros asumen que lo básico es algo dado, que se sobreentiende, y los alumnos deben saberlo; en consecuencia, no se explicitan las reglas, se dan por sabidas. La forma explícita es la que pone de manifiesto las reglas con que se trabajarán las conversaciones en clase, lo cual sucede con poca frecuencia.

4. Contexto y continuidad. Hay dos tipos de contextos: el lingüístico, que precede o sigue a lo que se ha dicho. En el caso de los no lingüísticos, están el tiempo, el lugar, la ocasión, personas implicadas, gestos y comunidad en la cual se despliega la actividad conversacional y dis- cursiva. En concreto, lo que se conoce y comprende. La continuidad está determinada por las recapitulaciones y los resúmenes en la actividad discursiva, en sí, el desarrollo del contexto en el tiempo.

5. Reglas básicas del habla en clase. Los denominados principios de cooperación: la calidad, es decir, contribución a lo dicho; la cantidad, esclarecimiento en los intercambios; la relevancia, que lo dicho aporte a la conversación; el modo, que sea inteligible lo que se diga. En general, que tenga sentido el discurso que se manifiesta, y que las expresiones sean compartidas; otorgarle sentido al habla en el salón de clase. Los alumnos son centrales aquí. Asimismo, indagar tres supuestos: el maestro hace las preguntas; el maestro conoce las respuestas; la repetición implica respuestas incorrectas por parte de los alumnos.

6. Ritual y principios. Entre los procesos de comunicación que permiten ir delineando el conocimiento compartido se encuentra el ritual, esa manera de proceder que tienen los alumnos, consistente en un tipo particular de hacer las cosas, que requiere una comprensión compartida. Del otro lado están los principios, esos elementos que explican el funcionamiento y proceder de las cosas o cómo se forja el conocimiento. Esos elementos que permiten sacar conclusiones al entender lo práctico y lo comprensivo en este rubro de comunicación y edificación del saber.

7. Contribuciones espontáneas. Las participaciones no contempladas, en cuanto a contenido y temas en el salón, pueden ser alentadas o desaprobadas, 
ello depende en buena medida del poder y control que el maestro quiera tener en el aula. En tal caso, se les puede alentar o denegar cuando los alumnos intentan contribuir a lo dicho en clase.

8. Conocimiento mediante pistas. El maestro realiza preguntas y proporciona pistas, que el estudiante debe comprender para que dé con las respuestas. El estudiante, en este caso, está construyendo, con ayuda de señales, el conocimiento. Ahí se muestra el discurso y en parte el conocimiento compartido.

9. Palabras y conceptos. Los discursos expresados en clase cobran forma, al menos, de dos maneras. Las palabras, material con que se hacen los discursos y conversaciones cotidianas, palabras que tienen distintos sentidos según el contexto donde se usen, y que son llevadas así, con disímil sentido, al salón de clases. Y los conceptos, aquellos con que se elaboran, en cierta medida, los discursos académicos y científicos; se espera que el alumno los integre a su conocimiento. Los conceptos tienen un significado independientemente del contexto; muestra de ello son quantum en física, paradigma en ciencia, andamiaje en psicología, representaciones sociales en psicología social, por mencionar algunos. Son dos formas de expresar la realidad social y sobre qué se edifica el conocimiento.

10. Negociaciones de significados. Entre las palabras y los conceptos, sentido y significado, se establece una negociación, esto es, para dar con los conceptos hay que usar palabras. De otra manera no se logra la comprensión. Las formas que despliegan los maestros, y las interrogantes que plantean los alumnos son materiales con que ello se logra. También entre maestros se presenta tal negociación. De ahí la necesidad de trabajar con sus discursos y conversaciones.

Dichas categorías-ejes, entre otras, posibilitan investigar, analizar y reconstruir las formas cómo se comparte el conocimiento. Esa es la tarea, hurgar estas maneras en las cuales el lenguaje se despliega para un mejor entendimiento en el ámbito escolar. De este modo, se dotaría de cercanía lo que en las aulas se narra, lo que se intenta explicar, lo que se pretende compartir, para así saberse partícipes de la edificación del conocimiento; crear comunión del saber, para que lo expresado en la escuela no resulte aburrido, tedioso ni carente de sentido.

Para concluir. Se ha dicho que el habla en el aula está organizada para la transmisión controlada del conocimiento. Desde la perspectiva aquí suscrita, se intenta abordar otra mirada y explorar la construcción social del conocimiento, saber cómo es que dos o más personas pueden establecer a través del lenguaje y sus discursos una continuidad de experiencias que sea en sí mayor que su habla o experiencia individual.

\section{Referencias}

Abbagnano, N. (1961). Diccionario de filosofía. México: Fondo de Cultura Económica. Astudillo, C., Rivarosa, A., \& Ortiz, F. (2008). El discurso en la formación de docentes de ciencias. Un modelo de intervención. 
En Revista Iberoamericana de Educación, 4(45), 2-14.

Bajtín, M. (1979). Problemas de la poética de Dostoievski. México: Fondo de Cultura Económica.

Bajtín, M. (2000). Yo también soy. (Fragmentos sobre el Otro). México: Taurus.

Billig, M. (1987). Thinking and arguing. A rhetorical approach to social psychology. Cambridge: Cambridge University Press.

Bruner, J. (1997). La educación, una puerta a la cultura. Madrid: Visor.

Candela, A. (2010). Time and espace: undergratuate Mexican pshysics in motion. Cultural Studies of Science Education, 5, 701-727.

Candela, A., Rockwell, E., \& Coll, C. (2009). ¿Qué demonios pasa en las aulas? La investigación cualitativa del aula. En CPU-e, Revista de Investigación Educativa, 8. Recuperado de http://www.redalyc.org/ articulo.oa?

Eco, U. (2000). Tratado de semiótica general. Barcelona: Lumen.

Edwards, D., \& Mercer, N. (2000). El conocimiento compartido: El desarrollo de la comprensión en el aula. Barcelona: Paidós.

Engels, F. (1876). El papel del trabajo en la transformación del mono en hombre. Moscú: Biblioteca de textos marxistas.

Fernández-Christlieb, P. (1994). Psicología social, intersubjetividad y psicología colectiva. En M. Montero (Coord.), Construcción y crítica de la psicología social (pp. 49-107). Barcelona: Anthropos.

Flores, G., Íñiguez, L., \& Martínez, A. (2015). Discurso y materialidad: Pensar las prácticas semiótico-materiales. Alpha, 40, 201-214.

Geertz, C. (1973). La interpretación de las culturas. Barcelona: Gedisa.

Gergen, K. (1994). Realidad y relaciones. Aproximaciones a la construcción social. Barcelona: Paidós.

Gergen, K. (2015). La dimensión poética: Posibilidades terapéuticas. En K. Deissler \& S. McName (Eds.), Filos y Sofía en diálogo (pp. 68-75). Ohio: Taos Institute Publications.

Lampolski, M. (2009). La teoría de la Intertextualidad y el cine. En D. Navarro (sel. y trad.), El pensamiento cultural ruso en Criterios I (pp. 78-145). La Habana: Centro Teórico-Cultural Criterios.

Marx, C. (1932). Manuscritos: economía y filosofia. Barcelona: Altaya.

Mead, G. H. (1934). Espíritu, persona y sociedad. Barcelona: Paidós.

Medina, A. (2007). Pensamiento y lenguaje. Enfoques constructivistas. México: McGrawHill.

Piaget, J. (1991). Seis estudios de psicología. Barcelona: Labor.

Sánchez, E., \& Rosales, J. (2005). La práctica educativa. Una revisión a partir del estudio de la interacción en el aula. En Cultura y Educación, 17(2), pp. 147-173.

Shotter, J. (1990). La construcción social del recuerdo y el olvido. En D. Middleton \& D. 
Edwards (Comp.), Memoria compartida. La naturaleza social del recuerdo y del olvido, pp. 137-155. Barcelona: Paidós.

Shotter, J. (1993). Realidades conversacionales. La construcción de la vida a través del lenguaje. Buenos Aires. Amorrortu.

Shotter, J. (2013). Wittgenstein y las raíces de la poesía social en las reacciones corporales espontáneas: La tercera esfera. En K. Deissler \& S. McName (Eds.), Filos y Sofía en diálogo (pp. 84-90). Ohio: Taos Institute Publications.

Silvestri, A., \& Blanck, G. (1993). Bajtín y Vigotsky: La organización semiótica de la conciencia. Barcelona: Anthropos.

Tajfel, H. (1981). Grupos humanos y categorías sociales. Barcelona: Herder.

Voloshinov, V. (1929). El marxismo y la filosofía del lenguaje. Madrid: Alianza.

Vygotsky, L. (1931). Desarrollo de las funciones mnemónicas y mnemotécnicas. En L. Vygotsky (Ed.), Obras Escogidas (tomo III, pp. 247-264). Madrid: Visor.

Vygotsky, L. (1932). El desarrollo de los procesos psicológicos superiores. México: Grijalbo.

Vygotsky, L. (1934). Pensamiento y lenguaje. Barcelona: Paidós.

Wertsch, J. (1988). Vygotsky y la formación social de la mente. Barcelona: Paidós.

Wertsch, J. (1991). Voces de la mente. Un enfoque sociocultural para el estudio de la acción mediada. Madrid: Visor.
Wertsch, J. (1997). Memoria colectiva: Cuestiones relacionadas con una perspectiva sociohistórica. En M. Cole (Ed.), Mente, cultura y actividad (pp. 183-188). México: Oxford. Wundt, W. (1912). Elementos de psicología de los pueblos. Barcelona: Alta Fulla.

Recibido el 2 de abril de 2014 Revisado el 15 de mayo de 2014 Aceptado el 19 de agosto de 2015 